\title{
Lactic acid in tumor microenvironments causes dysfunction of NKT cells by interfering with mTOR signaling
}

\author{
Di Xie ${ }^{1,2}$, Shasha $\mathrm{Zhu}^{1,2}$ \& $\mathrm{Li} \mathrm{Bai}^{1,2^{*}}$ \\ ${ }^{1}$ CAS Key Laboratory of Innate Immunity and Chronic Disease, CAS Center for Excellence in Molecular Cell Science, School of Life Sciences \\ and Medical Center, University of Science and Technology of China, Hefei 230027, China; \\ ${ }_{2}^{2}$ Innovation Center for Cell Signaling Network, Hefei National Laboratory for Physical Sciences at Microscale, Hefei 230027, China
}

Received November 15, 2016; accepted November 22, 2016; published online December 5, 2016

\begin{abstract}
Cellular metabolism has been shown to regulate differentiation and function of immune cells. Tumor associated immune cells undergo phenotypic and functional alterations due to the change of cellular metabolism in tumor microenvironments. NKT cells are good candidates for immunotherapies against tumors and have been used in several clinical trials. However, the influences of tumor microenvironments on NKT cell functions remain unclear. In our studies, lactic acid in tumor microenvironments inhibited IFN $\gamma$ and IL4 productions from NKT cells, and more profound influence on IFN $\gamma$ was observed. By adjusting the $\mathrm{pH}$ of culture medium we further showed that, dysfunction of NKT cells could simply be induced by low extracellular $\mathrm{pH}$. Moreover, low extracellular $\mathrm{pH}$ inhibited NKT cell functions by inhibiting mammalian target of rapamycin (mTOR) signaling and nuclear translocation of promyelocytic leukemia zinc-finger (PLZF). Together, our results suggest that tumor acidic microenvironments could interfere with NKT cell functions through metabolic controls.
\end{abstract}

lactic acid, NKT cell, IFN $\gamma$, mTOR, PLZF

Citation: Xie, D., Zhu, S., and Bai, L. (2016). Lactic acid in tumor microenvironments causes dysfunction of NKT cells by interfering with mTOR signaling. Sci China Life Sci. doi: 10.1007/s11427-016-0348-7

\section{INTRODUCTION}

NKT cells are CD1d-restricted T lymphocytes, which possess semi-invariant TCR, have effector phenotypes and recognize lipid antigens. Upon activation, NKT cells release abundant Th1 and Th2 cytokines and regulate functions of DCs, macrophages, B cells, NK cells and conventional T cells in a direct or indirect way (Bendelac et al., 2007). As important immune regulators, NKT cells promote the killing effects of NK cells and CTLs against tumor cells and also kill CD1d $\mathrm{d}^{+}$tumor cells directly (Fujii et al., 2013). Thus, NKT cells are ideal targets for anti-tumor immunotherapies.

*Corresponding author (email: baili@ustc.edu.cn)
Transferring in vitro expanded NKT cells or aGC-pulsed DCs showed significant prolonged mean survival time and stabilization of disease (Motohashi et al., 2006; Motohashi et al., 2009; Motohashi et al., 2011). However, some of those patients with low IFN $\gamma$ production showed no clinical effects (Motohashi et al., 2011). Additionally, decreased NKT cell numbers and impaired IFN $\gamma$ productions have been reported previously in cancer patients and are related to poor clinical outcome (Molling et al., 2007; Motohashi et al., 2011; Muhammad Ali Tahir et al., 2001). Thus, optimal IFN $\gamma$ production is important for the antitumor effects of NKT cells. And dysfunction of NKT cells would dampen their antitumor effects. Antigens and types of antigen-presenting cells are extrinsic factors modulating the cytokine responses of NKT 
cells (Bai et al., 2009; Bai et al., 2012). However, the factors causing dysfunction of NKT cells in tumor microenvironments are still unclear.

Activation of immune cells results in a metabolic reprogramming. Upon activation, naïve $\mathrm{T}$ cells undergo a switch from fatty acid oxidation (FAO) and oxidative phosphorylation to glycolysis in supporting their differentiation into effector cells such as Th1, Th2 and Th17 (Barbi et al., 2013). Interestingly, Tregs and memory CD8 T cells utilize oxidative phosphorylation for energy generation. Inhibiting glycolysis or enforcing FAO promotes differentiation of memory CD8 T cells and Tregs (Michalek et al., 2011; Pearce et al., 2009; Sukumar et al., 2013; van der Windt et al., 2012). And increased glycolysis has been shown to promote the functions and development of effector CD8 T cells and Th1 cells (Cham et al., 2008; Chang et al., 2013). Additionally, mammalian target of rapamycin (mTOR) signaling, which senses nutrient availability and controls cellular metabolisms, has been reported to regulate differentiation of distinct $\mathrm{T}$ lineages (Pollizzi and Powell, 2015). These results demonstrate a link between cellular metabolism and differentiation and function of immune cells. Thus, immune cells in solid tumors as well as in infection sites and inflammation tissues would show different phenotypes and functions from those in normal tissues due to their distinct metabolic microenvironments. Tumor microenvironments are gradually formed during the progression of tumors as indicated by exhaustion of nutrients and accumulation of lactic acid (Molon et al., 2016; Romero-Garcia et al., 2016), which have been shown to alter the phenotypes and functions of tumor resident immune cells through interfering with their cellular metabolism (Kouidhi et al., 2016; Molon et al., 2016). Nutrient depletion inhibits functions of
CTLs and drives DCs and macrophages to immunosuppressive phenotypes by inhibiting glycolysis (Chang et al., 2015; Krawczyk et al., 2010). And accumulation of lactic acid has also been shown to inhibit functions of CTLs and monocytes (Dietl et al., 2010; Fischer et al., 2007; Peter et al., 2015). Although the mechanisms by which cellular metabolism regulates NKT cell functions have not been reported, the dysfunction of NKT cells associated with tumors would hypothetically result from the impaired metabolisms in tumor microenvironments.

Here, we showed that accumulation of lactic acid in tumor environments caused dysfunction of NKT cells as indicated by dampened IFN $\gamma$ production and IL4 production to a less extent. Moreover, we demonstrated that low $\mathrm{pH}$ in culture medium was responsible for the dysfunction of NKT cells caused by lactic acid accumulation. Moreover, we observed impaired mTOR signaling and nuclear localization of promyelocytic leukemia zinc-finger (PLZF) in NKT cells in low $\mathrm{pH}$ culture medium. Our results suggest that acidification of tumor environments causes dysfunction of NKT cells by interfering with mTOR signaling.

\section{RESULTS}

\section{Lactic acid in tumor microenvironment inhibits NKT cell functions}

Lactate accumulation and acidification of extracellular environment are hallmarks of solid tumors. Tumor cell lines BT474, HCC1954, MDAMB231 and B16F10 were cultured for two days, and the different colours of culture medium indicated different amount of lactic acid productions (Figure 1A). To study the influences of tumor microenvironments on
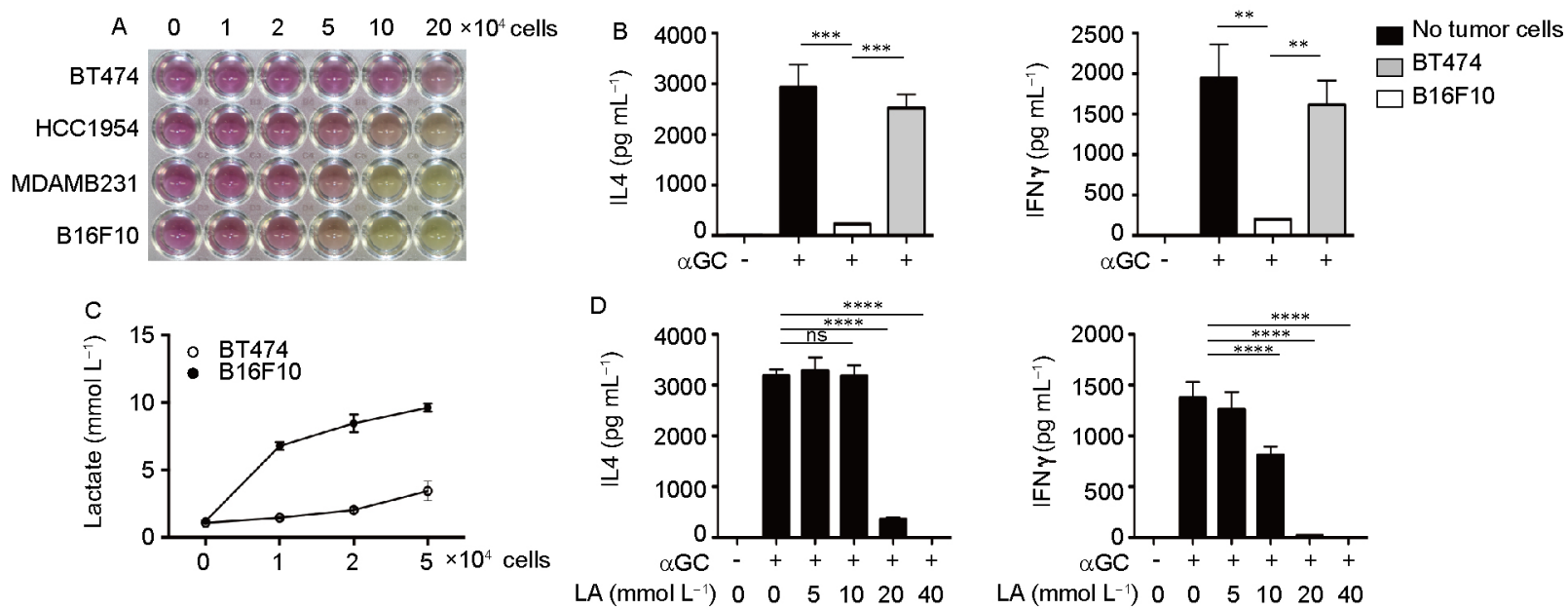

Figure 1 Lactic acid in tumor microenvironments inhibits functions of NKT cells. A, Productions of lactic acid from indicated tumor cell lines, as shown by colour of culture medium after two days culture. Data are representative of three independent experiments. B, IL4 and IFN $\gamma$ productions from NKT cells activated by RBL.CD1d cells and $\alpha \mathrm{GC}$ in the absence or presence of indicated tumor cells $\left(2 \times 10^{5}\right.$ cells $)$. Data are pooled from two independent experiments. C, Lactic acid productions from B16F10 cells and BT474 cells at indicated numbers after $24 \mathrm{~h}$ culture. The data are pooled from three independent experiments. D, IL4 and IFN $\gamma$ productions from NKT cells activated by RBL.CD1d cells and $\alpha$ GC in the absence or presence of lactic acid at indicated concentrations. The data are pooled from two independent experiments. Error bars are mean \pm SE. $* *, P<0.01 ; * * *, P<0.001 ; * * * *, P<0.0001$. 
NKT cell functions, NKT cells plus RBL.CD1d cells in upper chamber were co-cultured with tumor cells in lower plate in the presence of $\alpha \mathrm{GC}$ in transwell systems. Two tumor cell lines with different lactic acid productions were chosen based on the colour of culture medium. B16F10 cells releasing high level of lactic acid significantly inhibited IFN $\gamma$ and IL4 productions from NKT cells in transwell co-culture system. Whereas BT474, which produced less amount of lactic acid, showed no influence on cytokine productions from NKT cells (Figure 1B and C). To further investigate whether accumulation of lactic acid alone would result in the dysfunction of NKT cells, NKT cells and RBL.CD1d cells were co-cultured in the presence of $\alpha \mathrm{GC}$ with or without lactic acid treatment.
Consistently, lactic acid inhibited IFN $\gamma$ and IL4 productions in a dose dependent way, and more profound influence was observed on IFN $\gamma$ than on IL4 (Figure 1D).

\section{Extracellular acidification inhibits NKT cell functions in- dependent of TCR signaling}

Lactic acid accumulation causes acidification of extracellular environment. Thus, the dysfunction of NKT cells induced by lactic acid could be a result of dropped extracellular $\mathrm{pH}$. To test this possibility, we adjusted medium $\mathrm{pH}$ back to 7.3 in lactic acid treated groups by adding $\mathrm{NaOH}$. Interestingly, $\mathrm{NaOH}$ was capable to restore the IFN $\gamma$ and IL4 productions (Figure 2A). Next, we changed the $\mathrm{pH}$ of culture medium to
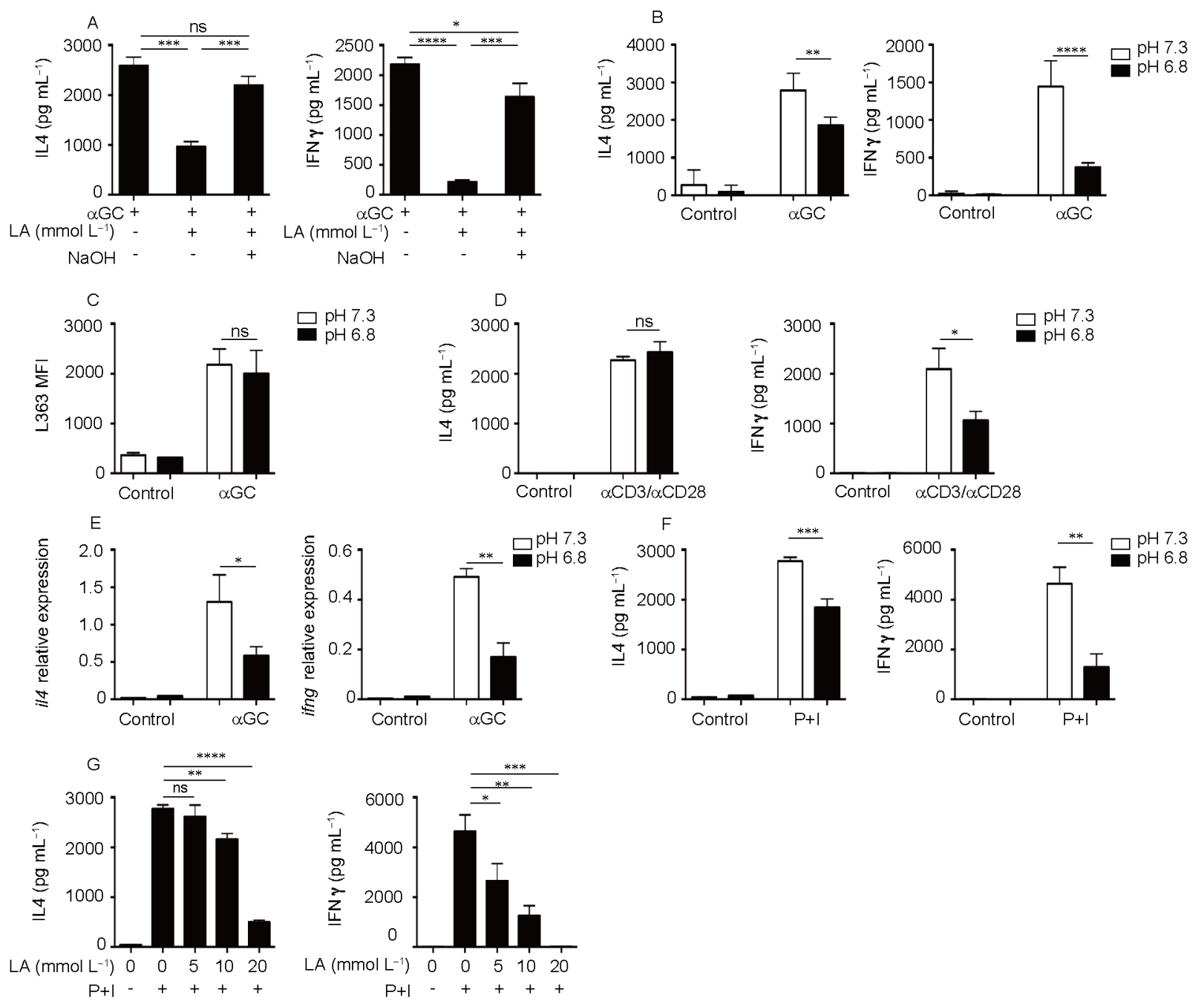

Figure 2 Low pH inhibits functions of NKT cells independent of TCR signaling. A, Cytokine productions from NKT cells activated by RBL.CD1d cells and $\alpha \mathrm{GC}$ in the absence or presence of lactic acid $\left(20 \mathrm{mmol} \mathrm{L}^{-1}\right)$ and with or without $\mathrm{pH}$ adjusted back to 7.3 by adding $\mathrm{NaOH}$. The data are representative of two independent experiments. B, Cytokine productions from NKT cells activated by RBL.CD1d cells and $\alpha \mathrm{GC}$ at $\mathrm{pH} 7.3$ or $\mathrm{pH} 6.8$. The data are pooled from two independent experiments. C, CD1d- $\alpha$ GC on cell surface was detected by L363. Mean fluorescence intensity of L363 was shown. The data are representative of two independent experiments. D, Cytokine productions from NKT cells activated by plate-coated anti-CD3 and anti-CD28 at pH 7.3 or pH 6.8. The data are representative of three independent experiments. E, mRNA levels of cytokines in NKT cells activated at pH 7.3 or pH 6.8 by RBL.CD1d cells pulsed with $\alpha$ GC. The data are representative of three independent experiments. $\mathrm{F}-\mathrm{G}$, Cytokine productions from NKT cells activated by PMA $\left(50\right.$ ng $\left.\mathrm{mL}^{-1}\right)$ and ionomycin $(1$ $\left.\mu \mathrm{mol} \mathrm{L} \mathrm{L}^{-1}\right)$ in $\mathrm{pH} 7.3$ or $\mathrm{pH} 6.8$ culture medium $(\mathrm{F})$, or in the absence or presence of lactic acid $(\mathrm{G})$. The data are representative of two independent experiments. Error bars are mean \pm SE. * $P<0.05 ; * *, P<0.01$; ***, $P<0.001 ; * * * *, P<0.0001$. 
6.8 by adding $\mathrm{HCl}$ without lactic acid, mimicking the $\mathrm{pH}$ in tumors in vivo. NKT cells and RBL.CD1d cells were co-cultured in presence of $\alpha \mathrm{GC}$ in normal medium or in $\mathrm{pH} 6.8$ medium. Consistently, extracellular acidification inhibited IFN $\gamma$ and IL4 productions from NKT cells (Figure 2B). And more profound influence was observed on IFN $\gamma$. These results suggested that change of $\mathrm{pH}$ but not accumulation of lactate caused dysfunction of NKT cells. To exclude the possibility that dysfunction of NKT cells was due to the impaired antigen presentation, we measured the level of CD1d- $\alpha$ GC complex on RBL.CD1d cell surface with antibody L363. Similar amount of surface CD1d- $\alpha$ GC complex was detected in cells culturing at $\mathrm{pH} 7.3$ and $\mathrm{pH} 6.8$ (Figure 2C). And in antigen presenting cell-free system, NKT cells were stimulated by plate-coated anti-CD3 and anti-CD28 in $\mathrm{pH} 7.3$ or $\mathrm{pH}$ 6.8 medium, and down-regulation of IFN $\gamma$ production from NKT cells was also observed at pH 6.8 (Figure 2D). Whereas no effect on IL4 production was observed. Thus, extracellular acidification inhibited NKT cell functions independent of influence on antigen presentation. Additionally, we showed that low $\mathrm{pH}$ inhibited cytokines at the transcriptional level (Figure 2E). To further investigate whether low $\mathrm{pH}$ influenced TCR signaling, we stimulated NKT cells with PMA plus ionomycin bypassing the TCR signaling in $\mathrm{pH} 6.8$ medium or in the presence of lactic acid. And under both conditions, we observed dysfunction of NKT cells (Figure 2F and G). Thus, extracellular acidification inhibited NKT cell cytokine productions by modulating pathways downstream TCR signaling.

\section{Extracellular acidification does not change cell viability}

To investigate whether the dysfunction of NKT cells was due to increased cell death in acidic environment, we stained NKT cells with propidium iodide (PI) after $24 \mathrm{~h}$ stimulation in normal medium or in pH 6.8 medium. Decreased dead cells were observed at $\mathrm{pH} 6.8$, excluding the possibility that increased mortality caused dysfunction of NKT cells (Figure 3).

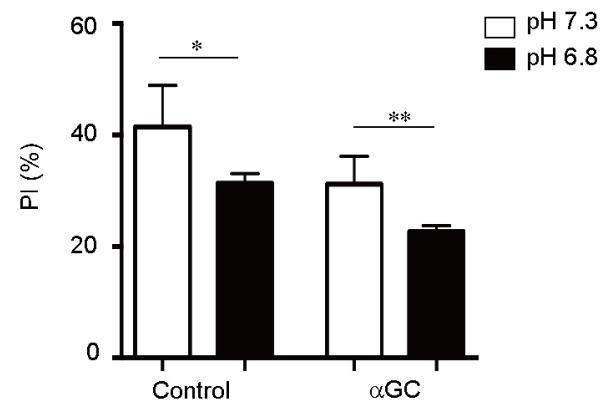

Figure 3 Low pH does not influence the viability of NKT cells. Percentages of $\mathrm{PI}^{+} \mathrm{NKT}$ cells after activation with RBL.CD1d cells and $\alpha \mathrm{GC}$ in $\mathrm{pH}$ 7.3 or $\mathrm{pH} 6.8$ medium for $24 \mathrm{~h}$. The data are pooled from two independent experiments. Error bars are mean \pm SE. *, $P<0.05 ;{ }^{* *}, P<0.01$.

\section{Extracellular acidification interfered with mTOR signal- ing in NKT cells upon activation}

mTOR signaling has been critically linked to cellular metabolisms and immunity by previous studies (Powell et al., 2012; Vitiello et al., 2015; Weichhart et al., 2015). Activation of mTOR signaling was observed in NKT cells upon activation. However, impaired mTOR signaling was detected in NKT cells activated in $\mathrm{pH} 6.8$ medium or in the presence of lactic acid, as indicated by less amounts of p-S6 and p-4E-BP1 (Figure 4A and B). And pH 6.8 medium dampened mTOR signaling to a lesser extent than $20 \mathrm{mmol} \mathrm{L}^{-1}$ lactic acid did, which was in consistence with their influences on cytokine productions. It has been reported that mTOR signaling regulates development and cytokine productions of NKT cells via controlling nuclear translocation of transcription factor PLZF (Shin et al., 2014). PLZF is a signature transcription factor for NKT cells, which controls development and effector programs of NKT cells (Savage et al., 2008). Nuclear localization is important for the functions of PLZF. In mTORC1 signaling deficient mice, diminished nuclear localization of PLZF and diminished cytokine productions were observed in NKT cells (Shin et al., 2014). In consistence with previous studies, we also detected less nuclear translocation of PLZF in NKT cells activated in the presence of lactic acid (Figure 4C). Thus, our results suggested that acidic tumor microenvironments caused dysfunction of NKT cells by interfering with mTOR signaling and PLZF nuclear translocation.

\section{DISCUSSION}

Immune evasion of tumor is the major reason for tumor progression. The underlying mechanisms include defective antigen presentations, impaired expression of costimulatory molecules, increased inhibitory mediators and accumulation of immunosuppressive cells (Liu and Cao, 2015; Mapara and Sykes, 2004). Moreover, warburg effect of tumor cells results in special microenvironments especially in solid tumors, which are characterized by nutrient depletion and low pH (Vander Heiden et al., 2009). Metabolic regulations on differentiation and function of immune cells have been reported recently. Similar as tumor cells, M1 macrophages, DCs, Th1 cells and CTLs utilize glycolysis for energy supply. Whereas the pro-tumor immune cells, such as M2 macrophages, regulatory DCs and Tregs, undergo oxidative phosphorylation (Biswas, 2015; Wang et al., 2014). And accumulation of lactic acid would influence cell functions by interfering with glycolysis. Together, competition for nutrients and accumulation of lactic acid would inhibit the development and functions of anti-tumor cells but favor the pro-tumor cells (Chang et al., 2015; Dietl et al., 2010; Fischer et al., 2007). Thus, tumor microenvironments could be another explanation for the failed immune surveillance 
A

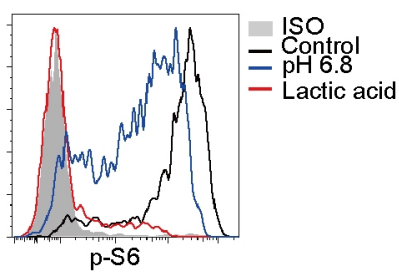

B

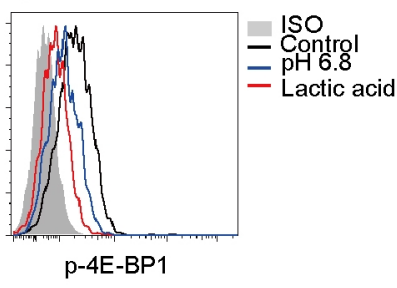

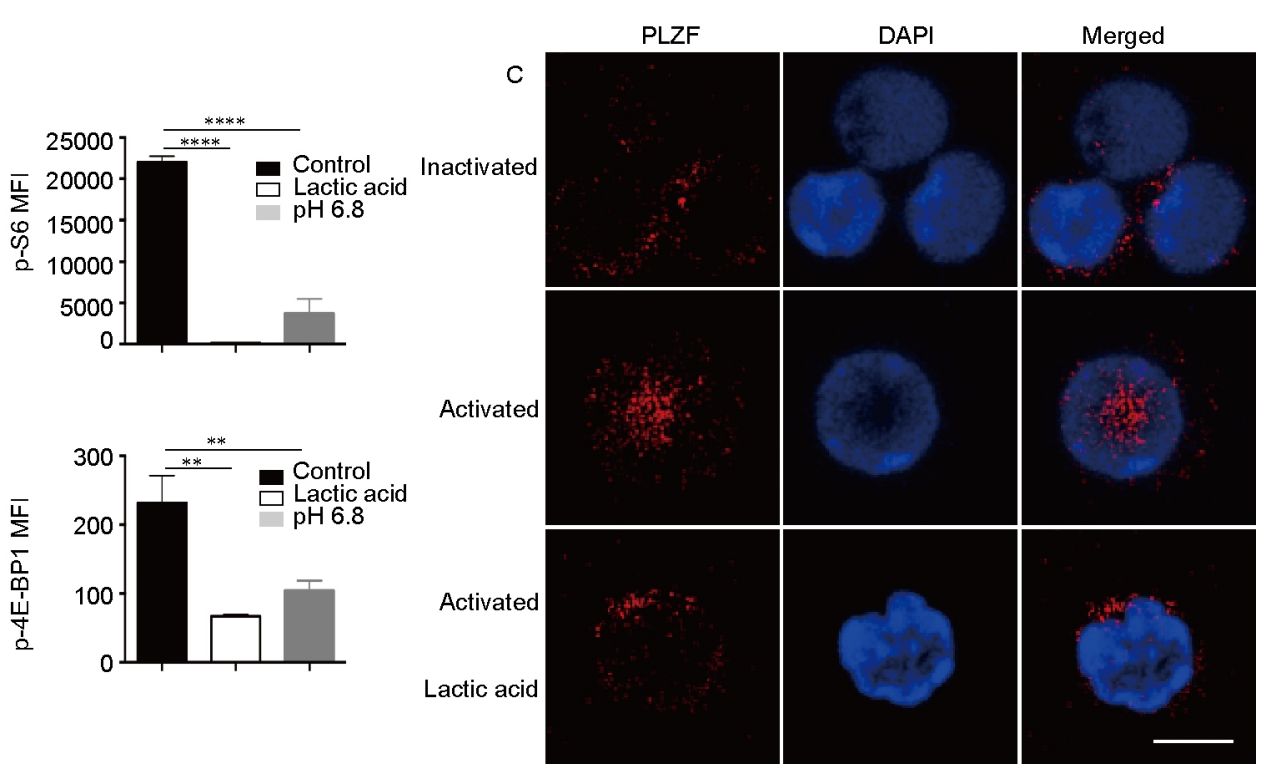

Figure 4 Low pH impairs mTOR signaling and translocation of PLZF in activated NKT cells. A and B, Phosphorylation of S6 (A) and 4E-BP1 (B) in NKT cells activated by plate-coated anti-CD 3 and anti-CD28 for $24 \mathrm{~h}$ in $\mathrm{pH} 7.3$ or $\mathrm{pH} 6.8$ medium or in the presence of $20 \mathrm{mmol} \mathrm{L}^{-1}$ lactic acid. Data are representative of two independent experiments. C, Localization of PLZF in NKT cells inactivated or activated by plate-coated anti-CD3 and anti-CD28 in the presence or absence of lactic acid $\left(20 \mathrm{mmol} \mathrm{L}^{-1}\right)$. Red, PLZF; blue, 4',6-diamidino-2-phenylindole, DAPI. Scale bars, $5 \mu \mathrm{m}$. Error bars are mean \pm SE. $* *, P<0.01$; $* * * *$, $P<0.0001$.

against tumors.

NKT cells, as the bridge of innate and adaptive immunity, serve as the first line of body defense. In addition to killing the CD1d expressing tumor cells directly, activation of NKT cells has been shown to promote the functions of NK cells and CTLs (Fujii et al., 2013). Due to these advantages, NKT cells are good candidates for immunotherapies against tumors. However, our results indicate a significant influence of tumor microenvironments on NKT cell functions. Dysfunction of NKT cells, especially diminished IFN $\gamma$ production, was induced by low $\mathrm{pH}$ in tumors (Figure 2). These results could explain the abnormal functions of NKT cells associated with tumors and the failed NKT cell-based immunotherapies. Additionally, we demonstrated that low $\mathrm{pH}$ impaired activation of mTOR signaling and downstream PLZF translocation (Figure 3). mTOR signaling has been previously shown to regulate nuclear localization of PLZF, which is important for NKT cell effector functions (Shin et al., 2014). Moreover, mTOR signaling and lactic acid have been reported to regulate glycolysis (Dietl et al., 2010; Powell et al., 2012). Thus, our results do not exclude the possibility that other factors influencing cellular metabolism, such as glycolysis, would also regulate NKT cell functions in tumor microenvironments. The mechanisms by which mTOR signaling regulates PLZF localization remain unclear. It has been reported that $\mathrm{mTORC} 1$ but not $\mathrm{mTORC} 2$ regulates nuclear localization of PLZF (Prevot et al., 2015).

It is not clear whether activating NKT cells and interfering with the production of lactic acid from tumor cells would result in a synergic effect. However, recent studies on anti-PD1 treatment demonstrate a very promising future for therapies targeting on both tumor immunity and tumor microenvironments. In addition to the blockade of inhibitory receptors, anti-PD1 treatment inhibits tumor growth by directly regulating tumor cell metabolism and reducing the glucose exhaustion in tumor microenvironments, which promotes CTL functions on the other side (Chang et al., 2015). Thus, except for the immune cells and checkpoint molecules, the tumor microenvironments would also be targets of immunotherapies. Normal tissue microenvironments are required to maintain the function of anti-tumor cells and also may be important for the migration of anti-tumor cells. Combination therapies are required in the future.

\section{MATERIALS AND METHODS}

Mice

$V \alpha 14$ Tg.cxcr $6^{g f p /+}$ mice were previously described and provided by Dr. Albert Bendelac (Bai et al., 2012; Scanlon et al., 2011). Mice were housed under specific pathogen-free conditions. All animal procedures were approved by the University of Science and Technology of China (USTC) Institutional Animal Care and Use Committee. And all experiments were performed in accordance with the approved guidelines.

\section{Cell culturing}

The B16F10 cells, MDAMB231 cells, BT474 cells and HCC1954 cells were cultured in DMEM medium (Gibco, USA) supplemented with 10\% FBS. RBL.CD1d cells and NKT cells were cultured in RPMI-1640 medium (Gibco) 
supplemented with $10 \%$ FBS and $50 \mu \mathrm{mol} \mathrm{L} \mathrm{L}^{-1} \beta \mathrm{ME}$.

\section{Cell enrichment}

Val4 Tg.cxcr $6^{g f p /+}$ mice were sacrificed and spleens were minced and passed through $70 \mu \mathrm{m}$ meshes. Cells were blocked with anti-CD16/32 for $15 \mathrm{~min}$, and stained with anti-CD4-APC for $30 \mathrm{~min}$ on ice. NKT cells were enriched with anti-APC microbeads (Miltenyi Biotec, Germany). In some experiments, purified NKT cells were obtained by sorting as $\mathrm{CD}^{+}$and $\mathrm{GFP}^{\text {hi }}$ cells from livers of $V \alpha 14 \mathrm{Tg}$. cxcr $^{g} \mathrm{fp}^{/+}$ mice.

\section{Activation of NKT cells}

For NKT cell activation, $3 \times 10^{4}$ RBL.CD1d cells and $4 \times 10^{4}$ enriched NKT cells were co-cultured in the presence of $\alpha \mathrm{GC}\left(1 \mu \mathrm{g} \mathrm{mL}^{-1}\right)$ or DMSO as control for $24 \mathrm{~h}$. Cytokines in supernatant were detected by CBA kit (BD, USA). To study the NKT cell functions in tumor microenvironments in vitro, indicated tumor cells $\left(2 \times 10^{5}\right.$ cells per well) were seeded in lower plate and enriched NKT cells were co-cultured with RBL.CD1d cells in upper chamber (Millipore, USA) in the presence of $\alpha \mathrm{GC}\left(1 \mu \mathrm{g} \mathrm{mL}{ }^{-1}\right)$. In cell-free stimulation assays, sorted NKT cells $\left(2 \times 10^{5}\right.$ per well) were stimulated with plate-coated anti-CD3 $\left(10 \mu \mathrm{g} \mathrm{mL}^{-1}\right)$ and anti-CD28 $\left(10 \mu \mathrm{g} \mathrm{mL}^{-1}\right)$ for $24 \mathrm{~h}$. Alternatively, purified NKT cells were stimulated with $1 \mu \mathrm{mol} \mathrm{L} \mathrm{L}^{-1}$ ionomycin and $50 \mathrm{ng} \mathrm{mL}{ }^{-1}$ PMA for $24 \mathrm{~h}$.

\section{Flow cytometry}

Cells were suspended in PBS buffer containing 1\% BSA, and blocked with anti-CD16/32 for $15 \mathrm{~min}$ on ice, then stained with monoclonal antibody for $30 \mathrm{~min}$ on ice. Monoclonal antibodies were listed here: purified anti-CD16/32 (93), anti-CD4 (GK1.5), anti-TCR $\beta$ (H57-597). All antibodies were purchased from BioLegend (USA). CD1d-PBS57 tetramer is provided by National Institute of Health (NIH) Tetramer Core Facility. To detect intracellular phospho-S6 (pS6), or phospho-4E-BP1 (p4E-BP1), sorted NKT cells were fixed with 2\% PFA and permeabilized with $90 \%$ pre-cooling methanol. Cells were stained with rabbit anti-pS6 (Ser235/236, Cell Signaling Technology, USA) or rabbit anti-p4E-BP1 (T37/46, Cell Signaling Technology) antibodies. For antigen presentation assays, RBL.CD1d cells were cultured in the presence of $\alpha \mathrm{GC}\left(1 \mu \mathrm{g} \mathrm{mL}{ }^{-1}\right)$ at different $\mathrm{pH}$ for $24 \mathrm{~h}$. Cells were digested by trypsin and washed with PBS buffer. After blocking, RBL.CD1d cells were stained with antibody against CD1d- $\alpha \mathrm{GC}$ complex (L363). Cells were acquired by FACSVerse (BD). And data was analyzed with FlowJo 7.6 software.

\section{Confocal}

Sorted NKT cells were stimulated by plate-coated anti-CD3 $\left(10 \mu \mathrm{g} \mathrm{mL}^{-1}\right)$ and anti-CD28 $\left(10 \mu \mathrm{g} \mathrm{mL}^{-1}\right)$ for $12-14 \mathrm{~h}$ in culture dishes. Cells were fixed with 4\% PFA for $15 \mathrm{~min}$, and then permeabilized with $0.1 \%$ Triton X-100 for $30 \mathrm{~min}$. Cells were washed and stained with PE-conjugated anti-PLZF $\left(4 \mu \mathrm{g} \mathrm{mL}^{-1}\right)$ and DAPI $\left(1.5 \mu \mathrm{g} \mathrm{mL}^{-1}\right)$ for $4 \mathrm{~h}$ on ice. Images were collected with an LSM 710 (Zeiss, Germany) inverted microscope. Data was analyzed with ImageJ.

\section{Statistical analysis}

Error bars represent SE. The statistical significance of differences between two groups was determined by the unpaired two-tailed student's $t$ test.

Compliance and ethics The author(s) declare that they have no conflict of interest.

Acknowledgements We thank Dr. S.L. Liu (USTC) for the kind gifts of MDAMB231 cells, HCC1954 cells, BT474 cells, and Dr. Z.G. Tian (USTC) for B16F10 cells and Dr. Steven A. Porcelli (Albert Einstein College of Medicine) for L363. We thank NIH Tetramer Core Facility for providing us CD1d-PBS57 tetramer. This work was supported by the Major State Basic Research Development Program of China (2013CB944902), National Natural Science Foundation of China (31271430, 31470859, 91542203), Fundamental Research Funds for the Central Universities, and Users with Potential (2015HSC-UP018).

Bai, L., Constantinides, M.G., Thomas, S.Y., Reboulet, R., Meng, F., Koentgen, F., Teyton, L., Savage, P.B., and Bendelac, A. (2012). Distinct APCs explain the cytokine bias of $\alpha$-galactosylceramide variants in vivo. J Immunol 188, 3053-3061.

Bai, L., Sagiv, Y., Liu, Y., Freigang, S., Yu, K.O.A., Teyton, L., Porcelli, S.A., Savage, P.B., and Bendelac, A. (2009). Lysosomal recycling terminates CD1d-mediated presentation of short and polyunsaturated variants of the NKT cell lipid antigen $\alpha$ GalCer. Proc Natl Acad Sci USA 106, 10254-10259.

Barbi, J., Pardoll, D., and Pan, F. (2013). Metabolic control of the Treg/Th17 axis. Immunol Rev 252, 52-77.

Bendelac, A., Savage, P.B., and Teyton, L. (2007). The Biology of NKT Cells. Annu Rev Immunol 25, 297-336.

Biswas, S.K. (2015). Metabolic reprogramming of immune cells in cancer progression. Immunity $43,435-449$.

Cham, C.M., Driessens, G., O'Keefe, J.P., and Gajewski, T.F. (2008). Glucose deprivation inhibits multiple key gene expression events and effector functions in $\mathrm{CD}^{+} \mathrm{T}$ cells. Eur J Immunol 38, 2438-2450.

Chang, C.H., Curtis, J.D., Maggi Jr., L.B., Faubert, B., Villarino, A.V., O'Sullivan, D., Huang, S.C.C., van der Windt, G.J.W., Blagih, J., Qiu, J., Weber, J.D., Pearce, E.J., Jones, R.G., and Pearce, E.L. (2013). Posttranscriptional control of $\mathrm{T}$ cell effector function by aerobic glycolysis. Cell 153, 1239-1251.

Chang, C.H., Qiu, J., O’Sullivan, D., Buck, M.D., Noguchi, T., Curtis, J.D., Chen, Q., Gindin, M., Gubin, M.M., van der Windt, G.J.W., Tonc, E., Schreiber, R.D., Pearce, E.J., and Pearce, E.L. (2015). Metabolic competition in the tumor microenvironment is a driver of cancer progression. Cell 162, 1229-1241.

Dietl, K., Renner, K., Dettmer, K., Timischl, B., Eberhart, K., Dorn, C., Hellerbrand, C., Kastenberger, M., Kunz-Schughart, L.A., Oefner, P.J., Andreesen, R., Gottfried, E., and Kreutz, M.P. (2010). Lactic acid and acidification inhibit TNF secretion and glycolysis of human monocytes. J Immunol 184, 1200-1209.

Fischer, K., Hoffmann, P., Voelkl, S., Meidenbauer, N., Ammer, J., Edinger, M., Gottfried, E., Schwarz, S., Rothe, G., Hoves, S., Renner, K., Timischl, B., Mackensen, A., Kunz-Schughart, L., Andreesen, R., 
Krause, S.W., and Kreutz, M. (2007). Inhibitory effect of tumor cell-derived lactic acid on human T cells. Blood 109, 3812-3819.

Fujii, S.I., Shimizu, K., Okamoto, Y., Kunii, N., Nakayama, T., Motohashi, S., and Taniguchi, M. (2013). NKT cells as an ideal anti-tumor immunotherapeutic. Front Immunol 4, 409.

Vander Heiden, M.G., Cantley, L.C., and Thompson, C.B. (2009). Understanding the Warburg effect: the metabolic requirements of cell proliferation. Science 324, 1029-1033.

Kouidhi, S., Noman, M.Z., Kieda, C., Elgaaied, A.B., and Chouaib, S. (2016). Intrinsic and tumor microenvironment-induced metabolism adaptations of $\mathrm{T}$ cells and impact on their differentiation and function. Front Immunol 7, 114.

Krawczyk, C.M., Holowka, T., Sun, J., Blagih, J., Amiel, E., DeBerardinis, R.J., Cross, J.R., Jung, E., Thompson, C.B., Jones, R.G., and Pearce, E.J. (2010). Toll-like receptor-induced changes in glycolytic metabolism regulate dendritic cell activation. Blood 115, 4742-4749.

Liu, Y., and Cao, X. (2015). Intratumoral dendritic cells in the anti-tumor immune response. Cell Mol Immunol 12, 387-390.

Mapara, M.Y., and Sykes, M. (2004). Tolerance and cancer: mechanisms of tumor evasion and strategies for breaking tolerance. J Clin Oncol 22, 1136-1151.

Michalek, R.D., Gerriets, V.A., Jacobs, S.R., Macintyre, A.N., MacIver, N.J., Mason, E.F., Sullivan, S.A., Nichols, A.G., and Rathmell, J.C. (2011). Cutting edge: distinct glycolytic and lipid oxidative metabolic programs are essential for effector and regulatory $\mathrm{CD}^{+} \mathrm{T}$ cell subsets. J Immunol 186, 3299-3303.

Molling, J.W., Langius, J.A.E., Langendijk, J.A., Leemans, C.R., Bontkes, H.J., van der Vliet, H.J.J., von Blomberg, B.M.E., Scheper, R.J., and van den Eertwegh, A.J.M. (2007). Low levels of circulating invariant natural killer T cells predict poor clinical outcome in patients with head and neck squamous cell carcinoma. J Clin Oncol 25, 862-868.

Molon, B., Calì, B., and Viola, A. (2016). T cells and cancer: how metabolism shapes immunity. Front Immunol 7, 20.

Motohashi, S., Ishikawa, A., Ishikawa, E., Otsuji, M., Iizasa, T., Hanaoka, H., Shimizu, N., Horiguchi, S., Okamoto, Y., Fujii, S., Taniguchi, M., Fujisawa, T., and Nakayama, T. (2006). A phase I study of in vitro expanded natural killer $\mathrm{T}$ cells in patients with advanced and recurrent non-small cell lung cancer. Clin Cancer Res 12, 6079-6086.

Motohashi, S., Nagato, K., Kunii, N., Yamamoto, H., Yamasaki, K., Okita, K., Hanaoka, H., Shimizu, N., Suzuki, M., Yoshino, I., Taniguchi, M., Fujisawa, T., and Nakayama, T. (2009). A phase I-II study of $\alpha$-galactosylceramide-pulsed IL-2/GM-CSF-cultured peripheral blood mononuclear cells in patients with advanced and recurrent non-small cell lung cancer. J Immunol 182, 2492-2501.

Motohashi, S., Okamoto, Y., Yoshino, I., and Nakayama, T. (2011). Antitumor immune responses induced by iNKT cell-based immunotherapy for lung cancer and head and neck cancer. Clin Immunol 140, 167-176.

Pearce, E.L., Walsh, M.C., Cejas, P.J., Harms, G.M., Shen, H., Wang, L.S., Jones, R.G., and Choi, Y. (2009). Enhancing CD8 T-cell memory by modulating fatty acid metabolism. Nature 460, 103-107.

Peter, K., Rehli, M., Singer, K., Renner-Sattler, K., and Kreutz, M. (2015). Lactic acid delays the inflammatory response of human monocytes. Biochem Biophys Res Commun 457, 412-418.

Pollizzi, K.N., and Powell, J.D. (2015). Regulation of T cells by mTOR: the known knowns and the known unknowns. Trends Immunol 36, 13-20.

Powell, J.D., Pollizzi, K.N., Heikamp, E.B., and Horton, M.R. (2012). Regulation of immune responses by mTOR. Annu Rev Immunol 30, 39-68.

Prevot, N., Pyaram, K., Bischoff, E., Sen, J.M., Powell, J.D., and Chang, C.H. (2015). Mammalian target of rapamycin complex 2 regulates invariant NKT cell development and function independent of promyelocytic leukemia zinc-finger. J Immunol 194, 223-230.

Romero-Garcia, S., Moreno-Altamirano, M.M.B., Prado-Garcia, H., and Sánchez-García, F.J. (2016). Lactate contribution to the tumor microenvironment: mechanisms, effects on immune cells and therapeutic relevance. Front Immunol 7, 52.

Savage, A.K., Constantinides, M.G., Han, J., Picard, D., Martin, E., Li, B., Lantz, O., and Bendelac, A. (2008). The transcription factor PLZF directs the effector program of the NKT cell lineage. Immunity 29, 391-403.

Scanlon, S.T., Thomas, S.Y., Ferreira, C.M., Bai, L., Krausz, T., Savage, P.B., and Bendelac, A. (2011). Airborne lipid antigens mobilize resident intravascular NKT cells to induce allergic airway inflammation. J Exp Med 208, 2113-2124.

Shin, J., Wang, S., Deng, W., Wu, J., Gao, J., and Zhong, X.P. (2014). Mechanistic target of rapamycin complex 1 is critical for invariant natural killer T-cell development and effector function. Proc Natl Acad Sci USA 111, E776-E783.

Sukumar, M., Liu, J., Ji, Y., Subramanian, M., Crompton, J.G., Yu, Z., Roychoudhuri, R., Palmer, D.C., Muranski, P., Karoly, E.D., Mohney, R.P., Klebanoff, C.A., Lal, A., Finkel, T., Restifo, N.P., and Gattinoni, L. (2013). Inhibiting glycolytic metabolism enhances $C D 8^{+} \mathrm{T}$ cell memory and antitumor function. J Clin Invest 123, 4479-4488.

Muhammad Ali Tahir, S., Cheng, O., Shaulov, A., Koezuka, Y., Bubley, G.J., Wilson, S.B., Balk, S.P., and Exley, M.A. (2001). Loss of IFN- $\gamma$ production by invariant NK T cells in advanced cancer. J Immunol 167, 4046-4050.

van der Windt, G.J.W., Everts, B., Chang, C.H., Curtis, J.D., Freitas, T.C., Amiel, E., Pearce, E.J., and Pearce, E.L. (2012). Mitochondrial respiratory capacity is a critical regulator of $\mathrm{CD}^{+} \mathrm{T}$ cell memory development. Immunity 36, 68-78.

Vitiello, D., Neagoe, P.E., Sirois, M.G., and White, M. (2015). Effect of everolimus on the immunomodulation of the human neutrophil inflammatory response and activation. Cell Mol Immunol 12, 40-52.

Wang, T., Liu, G., and Wang, R. (2014). The intercellular metabolic interplay between tumor and immune cells. Front Immunol 5, 358.

Weichhart, T., Hengstschläger, M., and Linke, M. (2015). Regulation of innate immune cell function by mTOR. Nat Rev Immunol 15, 599-614.

Open Access This article is distributed under the terms of the Creative Commons Attribution License which permits any use, distribution, and reproduction in any medium, provided the original author(s) and source are credited. 